\title{
SASSEN, SASKIA (2015). Expulsiones: brutalidad y complejidad en la economía global. Buenos Aires: Katz editores
}

\author{
LUis SUÁREZ ROJAS \\ Isuarezr@unmsm.edu.pe
}

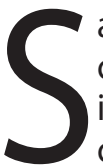

askia Sassen (La Haya, Países Bajos, 1949) es una de las sociólogas contemporáneas más audaces y provocadoras de nuestro tiempo. Lleva una intensa actividad académica, en distintas partes del mundo gracias a conferencias y congresos, siendo su espacio académico la Universidad de Chicago. Es una investigadora poseedora de una perspicacia intelectual, destaca su rigurosidad, su condición políglota; además tiene una historia inquietante. Su familia había desembarcado en Buenos Aires a fines de los años 40, pues su padre fue un SS holandés, que en su exilio bonaerense, estuvo cerca del inventor de la Solución Final. Su vida, un tanto errante, ha tenido un impacto decisivo en su mirada sociológica y sus preocupaciones intelectuales. En términos académicos, cursó estudios en la Universidad francesa de Poitiers y en la Universidad romana de La Sapienza, graduándose en Filosofía y Ciencias Políticas por la Universidad de Buenos Aires. Asimismo, en Estados Unidos amplió su formación en Sociología y Economía en la Universidad de Notre Dame, en Indiana, donde se doctoró en 1974.

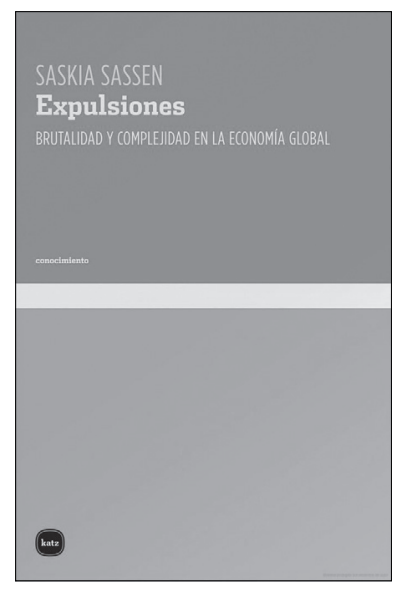

Desde finales de 1988 ha sabido posicionarse en la sociología contemporánea, gracias a investigaciones como The Mobility of Labor and Capital (Cambridge University Press 1988) y The Global City (Princeton University Press 1991). Estos trabajos, hoy esenciales para comprender nuestra contemporaneidad, le abrieron el camino a la comunidad sociológica mundial. Ella misma ha reconocido que acuñó el concepto "Ciudad Global", en referencia a urbes: Londres, Nueva York, París y Tokio, y en contraposición al concepto de "megaciudad". El impacto de sus obras se puede percibir en el número tan diverso de traducciones, cerca de veinte idiomas. Su actividad intelectual, le ha traído como consecuencia una serie de distinciones y galardones. Ha recibido múltiples diplomas de Doctor Honoris Causa; en el 2013 recibió el Premio Príncipe de Asturias de las Ciencias Sociales y fue elegida miembro de la Real Academia de las Ciencias de los Países Bajos y Chevalier de l'Ordre des Arts et Lettres por el gobierno francés.

Esta reseña aborda el libro publicado por Katz, en el 2015 titulado "Expulsiones. Brutalidad y Complejidad en la Economía Global". Aunque salió a la luz hace un par de años, las reflexiones de Saskia Sassen, han logrado un impacto muy reducido en 
nuestro medio y sus ideas no han circulado con la fluidez necesaria. Por lo tanto, esperamos contribuir con la divulgación de sus propuestas y presentar a más lectores el trabajo de esta socióloga.

Para ubicar mejor al lector será necesario señalar que el meollo central de su libro aborda el lado perverso y contradictorio de la globalización. No obstante, debe estar prevenido, pues no encontrará aquí una versión hegemónica del tema, concebido usualmente como algo abstracto y omnipresente de fuerzas. La autora desarrolla una sociología rigurosa y no se fía de ningún tipo de canon, ni moda académica, ni teórica. Por el contrario, su trabajo se orienta a cuestionar el papel de lo que ha llamado "categorías maestras", advirtiendo la capacidad de estas para iluminar y opacar, colocando en la sombra a ciertos aspectos de la realidad. En más de una vez, ella ha insistido que su ejercicio busca sacar de la penumbra todos aquellos elementos que son incómodos para la hegemonía académica. Desde mi perspectiva, su contribución reside en su ejemplo de inconformismo, su rigurosidad y anti-establisment. En ese sentido, su táctica analítica le permite moverse entre los bordes sistémicos que generan las "categorías maestras", mostrando sus limitaciones y perversidades. Algunas de ellas, por ejemplo, "migración", "globalización", "redes transnacionales", "capital", y otros.

La presente contribución es la continuidad de algunos de sus trabajos que han marcado la década del 2000. Gracias a la editorial Katz, en lengua española podemos leer su texto "Una sociología de la globalización" (2007), donde aborda los prolegómenos de su propuesta analítica; aquí el lector encontrará una serie de ensayos teóricos. Luego, publicó su libro "Territorio, autoridad y derechos: de los ensamblajes medievales a los ensamblajes globales" (2010), un trabajo voluminoso, notable por su esfuerzo titánico, denso por sus reflexiones teóricas y con una riqueza en datos empíricos. Este ambicioso reto, combina la reflexión sociológica y económica, con una perspectiva histórica. Su propósito ha sido comprender cómo la globalización es en realidad parte de un nuevo ensamblaje institucional que redefine el territorio y las fronteras del Estado-nación; proceso que pone en jaque al Estado (como tradicionalmente lo pensamos) "desnacionalizando" aquello que se ha constituido históricamente como nacional. Esta investigación se articula a partir de tres ejes: territorio, autoridad y derechos, los cuales, a lo largo de la historia se han reconstruido en "ensamblajes.

Justamente, su libro "Expulsiones: brutalidad y complejidad en la economía global" (2015) constituye la continuidad de su línea crítica sobre la globalización. El texto se organiza en cinco partes, una introducción; un capítulo analítico titulado "Economía en contracción, expulsiones en expansión"; acompañado por tres estudios de caso; por un lado, el mercado global de tierras; por el otro, las finanzas; y finalmente un estudio sobre tierra muerta y agua muerta. Estudios muy sugerentes, cargados de una riqueza empírica, construida con el dato desde el suelo. Además, un capítulo final de conclusiones que permiten redondear las ideas expuestas en el libro.

En la introducción sugiere una serie de pista que el lector debe tomar en consideración para entender esta propuesta tan heterodoxa. En principio busca examinar las nuevas lógicas de expulsión de los campos sociales y económicos, remitiéndonos a 
modos de expulsión "complejos" que tienen en común su condición aguda. Para la autora, dichas dinámicas son tan extremas como los procesos de selección salvaje. Su táctica analítica la lleva a tomar precauciones ante las categorías maestras, así, el concepto de expulsiones busca revisitar y mirar de manera crítica la "desigualdad creciente" como forma de aludir las "patologías del capitalismo". Un aspecto clave en su argumento lo constituyen las lógicas de expulsión coexisten con el crecimiento económico. Tales expulsiones no son espontáneas, sino "hechas" por instrumentos (políticos, técnicas y sistemas complejos). Usualmente, su análisis presente paradojas que desafían el razonamiento hegemónico, por ejemplo, sugiere que las políticas económicas crean un mundo complejo al mismo tiempo que producen brutalidades elementales. Asimismo, plantea otro enigma sociológico, se refiere a que si bien los Estados desarrollaron capacidades orientadas al bienestar, en la actualidad ellos han buscado "desmembrar lo social a través de la desigualdad extrema, para destruir buena parte de la vida de la clase media prometida por la democracia liberal, para expulsar a los pobres y vulnerables de tierras, empleos y hogares, y para expulsar a trozos de la biosfera de su espacio vital" (pág. 15).

Para el razonamiento de las "expulsiones", es sustancial retener las "dinámicas sistémicas subterráneas" que muy difícilmente se puede apreciar si utilizamos "categorías maestras" como economía capitalista, entre otros. Ella se refiere a lógicas analíticas que operan lejos de ser visibles y que podrían cuestionar los conceptos más recurrentes y típicos que organizan la comprensión de la sociedad e incluso la biosfera. Su hipótesis consiste en que "debajo de las especificidades nacionales de las diversas crisis nacionales se encuentran tendencias sistémicas emergentes conformadas por unas pocas dinámicas básicas" (Pág 17).

Complementariamente, Sassen sugiere que debemos comprender que los "oprimidos" de hoy sobreviven a la distancia de sus opresores, y eso impone un desafío a nuestras maneras clásicas de pensar dichas relaciones empíricas. En su mirada, el "opresor" no está en ningún centro visible, y lo constituye un sistema complejo, que combina personas, redes y máquinas que pueden localizarse usualmente en las ciudades globales. En mi perspectiva, su análisis ofrece una salida a la trampa rígida de la lógica del centro-periferia.

En el segundo capítulo titulado "Economía en contracción, expulsiones en expansión", Sassen sugiere que "mi tesis es que estamos presenciando la construcción no de élites predatorias sino de 'formaciones' predatorias, una combinación de élites y capacidades sistémicas con las finanzas (aspecto sustancial) que presiona hacia la concentración aguda" (Pág. 24). Su razonamiento hace evidente una serie de estrategias para la captación de riqueza, lo cual trae consecuencias graves como la creciente desigualdad. Todo esto debe leerse a partir de las capacidades sistémicas en tanto conjunto de innovaciones técnicas, financieras, de mercado y habilitación gubernamental. Según la autora, desde 1980 se ha organizado un proceso que expulsa gente de la economía y la sociedad. Si antes teníamos economías que absorbía fuerza de trabajo, ahora existen lógicas marcadas por el desempleo, pobreza, suicidio y desplazamiento de la tierra. Además, debemos leer este proceso según los contextos, puesto tales situaciones no se dan de la misma manera en el norte global que en el sur global, en ambos casos encontramos evidencia de 
constantes expulsiones particulares. Hoy, es cada vez más central la acumulación de la riqueza en pocas manos y firmas poderosas, quienes toman decisiones que implican a la mayoría del mundo.

Luego, nos ofrece un conjunto de estudios empíricos. Su ejercicio se acerca al mercado global de tierras, para advertir el entramado complejo de instrumentos y estrategias que orientan la compra de tierra a mano de burguesías, aún cuando esto es parte de la historia moderna, el problema medular consiste en el crecimiento notable de "propiedad extranjera está alterando en forma significativa el carácter de economías locales, en particular la propiedad de la tierra y reduciendo la autoridad soberana del Estado sobre su territorio" (Pág 132). El tema de fondo es que las tierras compradas no son tierras vacías, como suele pensarse desde la hegemonía. En realidad, constituyen vastas extensiones de territorio nacional modelado por pueblos y agricultura de pequeños propietarios. Lo que podría generar una desnacionalización dentro de Estados nacionales y agujeros en el territorio nacional soberano. El siguiente estudio analiza las hipotecas subprime y el colapso del sistema financiero. En este trabajo, Sassen señala que el aspecto problemático es que la forma cómo está organizado el campo de las finanzas, pues facilita la reproducción de formas de expulsión, siendo agresivas, egoístas e invasoras. Las finanzas pueden tener un potencial redistributivo, como el de China, al invertir en infraestructura, manufactura y otros; pero lo que apreciamos es que el capital financiero nos conduce a enormes concentraciones de riqueza y poder. Su tercer caso se tituló "Tierra Muerta, Agua Muerta", aquí señala que existen dinámicas más profundas e invisibles que atraviesan a países y lugares, en este contexto, muchos segmentos de la biosfera están siendo expulsados de su espacio vital, deviniendo en tierra muerta y agua muerta, en esa línea, "demasiados ciudadanos y demasiado de la biosfera son sometidos al uso y abuso, sin ninguna consideracion por su salud o prosperidad" (pág 235).

Hacia la conclusión del libro, Sassen nos ofrece ideas nuevas que refrescan y oxigenan las estructuras densas de pensamiento hegemónico sobre el capitalismo y la globalización. Considerando el papel que juega una "categoría maestra" y su capacidad para colocar aspectos de la vida social en las penumbras conceptuales, propone el ejercicio de moverse analíticamente en el filo del sistema. En esa perspectiva señala que:

"El objeto de indagación en este libro es el filo del sistema. La principal dinámica al filo del sistema es la expulsión de los diversos sistemas en juego: económico, social y biosférico. Ese filo es fundamentalmente distinto de la frontera geográfica en el sistema interestatal. El foco en el filo proviene de la hipótesis central que organiza este libro: que el paso del Keynesianismo a la era global, de privatizaciones, desregulación y fronteras abiertas para algunos implicaba un pasaje de una dinámica que atraía gente. Ese pasaje de la incorporación a la expulsión podría estar iniciándose tambien en China y la India" (Pág, 237)

Su propuesta le permite moverse analíticamente en el filo del sistema, para denunciar que hemos caído en una espiral peligrosa. Solo el crecimiento económico favorece a unos pocos en el planeta y se refuerza por complejos mecanismos institucionales y 
jurídicos. Esto nos enfrenta a una paradoja, pues mientras el discurso se orienta a la reducción de las brechas, en la práctica se busca la rentabilidad extrema de procesos muy básicos. En su razonamiento, todo está cada vez más al servicio de crecimiento económico corporativo, y aunque se pondere la idea de bienestar para todos, las corporaciones buscan su propio bienestar. Esto es parte de una tendencia sistémica por debajo de las formas hegemónicas de pensar en la economía y política en tiempos de globalización. En último termino lo que se busca es consolidar dinámicas básicas para el lucro y el enriquecimiento ilimitado por encima de la biosfera.

Sassen es parte del grupo de investigadores interdisciplinarios que vienen a renovar las ciencias sociales, con un aire fresco, crítico, heterodoxo, al mismo tiempo que ofrece sólidos argumentos. Este ejercicio le permite ir más allá del típico "aquíahora". Su trabajo nos recuerda la importancia de combinar la larga duración y corta duración, de maestros como Fernand Braudel, escapando de las trampas del estructuralismo holista de Wallerstein. Su práctica sociológica nos ofrece el ejemplo de un diálogo fructífero con las contribuciones de Giovanni Arrighi, Samir Amin y otras miradas heterodoxas por ejemplo Yanis Varoufakis. Considero que sus reflexiones ofrecen claves nuevas para repensar este lado del mundo. 